\title{
PRERROGATIVAS ESTATAIS, INTEGRAÇÃO REGIONAL E LÓGICA DISTRIBUTIVA*
}

\author{
MARCELO de A. MEDEIROS
}

\begin{abstract}
"Quando há vantagens na cooperação, são possíveis todos os tipos de arranjos que beneficiam cada parte comparados à ausência de cooperação. Deve-se então perguntar se a distribuição de vantagens é justa e aceitável, e não unicamente se há vantagens para todos os interessados" Amartya Sen (Nobel de Economia, 1998)1
\end{abstract}

O desmantelamento do Estado-nação ao longo das últimas décadas gerou um aumento considerável da entropia na arena internacional. Numa tentativa de criar uma nova ordem e reduzir o caos existente, a unidade de sobrevivência - na acepção de Norbert Elias ${ }^{2}$ - parece se deslocar da secular fórmula westfaliana rumo a um paradigma ainda em construção, a saber, o encarnado pelos processos de integração regional. Sem embargo, vê-se emergir estes processos como agentes catalisadores da inserção de um Estado-nação decadente no sistema internacional.

\footnotetext{
* A versão original deste texto foi apresentada no X Congresso da Federação Internacional de Estudos sobre América Latina e Caribe, Moscou, 2001.

1 Sen, Amartya, "Dix vérités sur la mondialisation", Le Monde, 19/07/01.

2 Elias, Norbert. La société des individus. Paris, Fayard, 1987.
} 
As sociedades nacionais procuram reduzir o impacto do fenômeno de globalização através do reforço dos espaços integrados, que devem assumir, doravante, um papel reivindicado outrora pelos Estados nacionais, estes se encontrando, na realidade, ultrapassados por uma construção econômica indo além de suas fronteiras. Constata-se, pois, a conformação progressiva de uma defasagem entre o político e o econômico, o Estado não sendo mais capaz de exercer suas prerrogativas históricas.

Todavia, na sua dupla missão - a de formulador e a de agente de implementação de políticas públicas - os espaços integrados hesitam entre uma cooperação com traços confederais e uma integração com vocação federal. Em razão de um exercício absoluto de soberania que perdura há séculos, o Estado-nação tem dificuldades em abdicar de seu poder, mesmo se ele esta consciente que a sua sobrevivência passa pela via da integração regional. Assim, a lógica supranacional se confronta à lógica intergovernamental, a primeira evocando a necessidade de eficiência e de um poder politico capaz de domar as forças econômicas ; a segunda apontando a necessidade de se respeitar as particularidades nacionais e a prática democrática.

Nesse contexto, propõe-se de escrutar o lugar das regiões periféricas no seio dos processos de integração regional, na medida em que são elas as que mais dependem dos poderes públicos - sejam eles estatais ou supraestatais. Parte-se da hipótese que a ausência de instâncias supranacionais dificulta a distribuição dos ganhos obtidos pela dinâmica integracionista e que as diferenças intra-regionais podem ser acentuadas se mecanismos de compensação não forem instaurados. Para tal, a Uniao Européia (UE) e o Mercado Comum do Sul (Mercosul) são escolhidos como objetos de análise.

A questão da soberania é considerada num primeiro tempo com o fito de balizar a pletora de interpretações que se forja ao longo dos séculos em torno de sua gênese. Em seguida analisa-se o fenômeno de integração regional sob uma perspectiva teórica, procurando associá-lo, pari passu, à crise do Estado-nação e à noção de supranacionalidade. Num terceiro momento introduz-se o problema da multitude de periferias nos diversos modos de regulação da União Européia e do Mercosul para, finalmente, desembocar-se no estudo da lógica distributiva. Uma conclusão expõe, então, alguns elementos de reflexão.

\section{DA QUESTÃO DA SOBERANIA}

Sem dúvida emblemática, a queda de Constantinopla, em 1453, cristaliza um conjunto de metamorfoses que, paulatinamente, anuncia a 
conformação do Estado-nação moderno. Suas raízes mais profundas se nutrem do patrimônio helênico-romano, reinterpretado, durante a Idade Média, pelo prisma de homens de Igreja como o dominicano Tomás de Aquino ou os franciscanos Duns Scot e Guilherme de Occam, assim como pela visão de leigos como Marsílio de Pádua e, posteriormente, Nicolau Maquiavel, Jean Bodin e Thomas Hobbes.

Retomando o postulado aristotélico que considera o homem naturalmente propenso ao jogo social e o inserindo na construção dualista cristã, Tomás de Aquino forja a idéia do indivíduo simultaneamente membro da cidade temporal - humanitas - e da cidade espiritual - christianitas. A primeira, pertencente a uma ordem delegada, de causas secundárias, accessível através da razão, permite a descoberta das regras da cidade justa e, assim, de elaborar um direito natural que se impõe ao príncipe, mas que lhe confere o controle de seus súditos e, consequentemente, a obtenção de obediência civil. A segunda, ao contrário, sugere uma cidade mística e sobrenatural, ancorada na Revelação, e acessível através da fé e não através da razão. Essas reflexões de Santo Tomás marcam a inserção da razão e do jusnaturalismo na história do pensamento ocidental. Do ponto de vista político, stricto sensu, ele reforça sobremaneira a noção de coexistência de soberanias - a saber : a autoritas, incarnada pelo papa, e a potestas exercida pelo príncipe - introduzidas precedentemente pelos Sumos Pontífices Gelásio I e Gregório VII ${ }^{3}$.

Todavia, essa dualidade de jurisdição, fundada na idéia de natureza e de razão humana, repousa no argumento de limitação da soberania omnipotente de Deus. Duns Scot e Guilherme de Occam vão, então, para enfrentar tal dilema, inserir o conceito de vontade. Assim como somente a vontade de Deus é capaz de discernir o que é possível, sendo omnisciente, omnipresente, absoluta ; assim, só a vontade dos homens cria o domínio temporal, através do exercício do livre arbítrio. Tal exercício não se baseia na idéia de natureza, mas no princípio de solidariedade, calcando-se em mecanismos contratuais e produzindo um direito positivo. A via moderna franciscana anuncia, assim, três elementos constitutivos do Estado moderno :

(i) a idéia de vontade contratual criadora da cidade, introduzindo a temática do contrato social - que será posteriormente resgatada por Rousseau ; (ii) a interpretação do indivíduo como sujeito

${ }^{3}$ Cf. Badie, Bertrand, La pensée politique vers la fin du XVIème siècle : héritages antique et médiéval. in Ory, Pascal (org.). Nouvelle histoire des idées politiques. Hachette, Paris, 1987. 
emancipado da tutela comunitária ; (iii) a visão de um sistema normativo coercitivo derivado do exercício da soberania ${ }^{4}$.

É a Marsílio de Pádua, porém, que a via moderna deve sua sistematização no plano político. Em seu Defensor Pacis, o teólogo italiano combate as pretensões de João XXII no domínio temporal, erigindo os princípios individualistas e positivistas tratados, outrora, pelos franciscanos essencialmente a um nível filosófico e teológico. O que é particularmente notável é que Marsílio de Pádua associa a idéia de vontade ao conceito de poder político, concebendo este último enquanto dinâmica de relações de força entre atores.

Essas relações de força entre atores, contudo, serão balizadas no seio do Estado moderno nascente por instituições que se inspiram nos mecanismos eclesiásticos de administração territorial da Cúria. É, de fato, a prática gerencial da Igreja que familiariza as populações aos dogmas da centralidade e da representação, consignando-as a associar competência territorial e hierarquia de autoridades, e.g., dioceses, paróquias, etc. Logo, as cogitações políticas de Marsílio de Pádua permanecem tributárias, ao menos provisoriamente, do modus operandi empregado pela Igreja Católica Apostólica Romana para administrar seu patrimônio. Esse mimetismo institucional, presente na gênese do Estado moderno, procura, na verdade, mobilisar recursos simbólicos e reais afim de instaurar um processo de legitimação de soberania que ele reivindica na arena internacional frente aos seus pares 5 .

$\mathrm{Na}$ ausência de agentes reguladores tais como o Santo Império Romano Germânico ou os Estados Pontificais, a sobrevivência do Estado moderno recai, desse modo, em sua capacidade em responder aos desafios da nova ordem internacional. O pensamento político, então, emerge, ao longo dos séculos XV e XVI, como a resultante de uma imbricação entre, por um lado, perspectivas holísticas e individualistas e, por outro lado, entre direito natural e positivo. Todavia, dessa imbricação, surge uma necessidade premente de conferir ao príncipe um máximo de autoridade, que ouse tocar no sacrossanto poder de lgiferação, até então assentado na prática costumeira. É o que faz Nicolau Maquiavel, propondo a instrumentalização da autoridade máxima na pessoa do príncipe. Ele elabora um verdadeiro tratado de ciência do poder $^{6}$, marcado por uma opção clara pela fé positivista e que ergue os alicerces do poder soberano indivisível.

\footnotetext{
4 Ibid.

5 Cf. Laroche, Josepha. Politique Internationale. Paris, L.G.D.J, 1998.

${ }^{6}$ Cf. Maquiavel, Nicolau. Le Prince. Paris, Gallimard, 1978 ( publicado inicialmente em 1513).
} 
Subseqüentemente, no bojo das idéias de Maquiavel, Jean Bodin talha o conceito de majestas, concebendo-o como o poder absoluto e soberano do monarca 7 . Doravante, mesmo se o espectro jusnaturalista e o das leis divinas ainda pairam marginalmente sobre o Estado moderno - rastro da teologia medieval - o rei assume o poder de legiferação e o papel de sumo soberano ${ }^{8}$. Se uma diferenciação teórica entre Absolutismo e Despotismo se impõe e se mostra presente no trato do exercício da soberania pelos pensadores da época, ela se faz, porém, de maneira tênue no que concerne as suas respectivas práticas.

Thomas Hobbes, desenvolvendo noções como a seditiosa opinio - que considera como revolucionária a idéia de que o indivíduo conserve o discernimento entre o bem e o mal, cabendo este papel exclusivamente ao soberano - ou a de imperium absolutum - entendendo que o monarca é depositário de uma soberania absoluta, hermeticamente fechada a toda lei exterior a ela - constrói um Leviatã que incarna o único meio de domar o estado de natureza que marca as arenas nacional e internacional ${ }^{9}$. Só assim o Estado pode se perpetuar e garantir a sobrevivência dos indivíduos que o compõem.

Naturalmente, essa tendência absolutista do Estado moderno será contestada, posteriormente, por filósofos do calibre de John Locke, do Barão de Montesquieu ou de Jean-Jacques Rousseau, entre outros. O exercício interno da soberania real parece então dever se coadunar com os anseios de uma sociedade civil cada vez mais consciente de seu poder. Contudo, isso não significa que o monolitismo soberano endógeno seja questionado. Noções tais que representatividade, delegação de poder, maioria/minoria, voto, entre outras, são desenvolvidas, mas não interferem no gozo pleno da soberania pela autoridade constituída. O que se verifica é uma tendência visando ao estabelecimento de mecanismos de enquadra-

${ }^{7}$ Cf. Bodin, Jean. Six Livres de la République. in Corpus des auvres de philosophie en langue française. Paris, Fayard, 1986 (publicado inicialmente em 1576).

8 "La monarchie royale ou légitime, écrit Jean Bodin, est celle où les sujets obéissent aux lois du monarque et le monarque aux lois de la nature... la monarchie seigneuriale est celle où le Prince est fait seigneur des biens et des personnes par le droit des armes et de bonne guerre". Goulemot, Jean-Marie. Etat. in Ory, Pascal (org.), Nouvelle histoire des idées politiques. Hachette, Paris, 1987.

9 O próprio Hobbes transpõe a imagem do estado de natureza às relações entre soberanos, comparando-os a gladiadores: "De là vient que les rois, dont le pouvoir est le plus grand de tous, tournent leurs efforts vers le soin de le rendre sûr, à l'intérieur du pays par des lois, à l'extérieur par des guerres". Apud. Sernaclens, Pierre de. Mondialisation, souveraineté et théories des relations internationales. Paris, Armand Colin, 1998. 
mento do poder real - que se reificam, sobretudo, pelo fortalecimento da autoridade parlamentar - assim como uma tentativa de conformação de dispostivos institucionais capazes de privilegiar o exercício pro tempore do poder, mas garantindo a estabilidade de sua transição.

Assim, Locke estabelece a existência de dois pactos: um que funda a sociedade e é indissolúvel, outro que ergue um governo, mas é passível de desintegração. Pode-se, então, ter uma dissolução do poder político, enquanto a organização social perdura. O povo sendo omnipotente e detentor absoluto da soberania, esta assume um caráter delegativo e revogável. $\mathrm{O}$ poder soberano somente existe se ele contribui aos fins do pacto social, respeita a lei natural e conserva a forma pré-estabelecida quando da convenção política inicial ${ }^{10}$.

Quanto a Montesquieu, ele forja uma doutrina constitucional ${ }^{11}$ dominada por três princípios :

(i) tudo deve estar subordinado ao respeito da lei, (ii) o exercício do poder deve ser moderado e (iii) é necessário que o poder freie o poder ${ }^{12}$. E nesse contexto que Monstesquieu estabelece a tripartição do poder dentro do Estado. Ele restringe, porém, ao Legislativo e ao Executivo o exercício da soberania, o Judiciário assumindo simplesmente o papel de controle: "O poder soberano não deve ser atribuído a um órgão simples - um único indivíduo, ou uma câmara única. Cumpre confiá-lo a um órgão complexo, formado de vários elementos diferentes e heterogêneos, encarnando princípios, forças políticas distintas, que o exercerão conjuntamente, juntas"13.

Jean-Jacques Rousseau, menos institucionalista que Montesquieu, refuta a definição hobbesiana do estado de natureza como o de guerra de todos contra todos e opõe-se à concepção de Locke de uma sociabilidade nata do homem. Para ele o corpo político legítimo é composto por indivíduos autônomos, livres e iguais em direito, que participam diretamente dos negócios do Estado e que formam, enquanto cidadãos, o povo soberano ${ }^{14}$. Mas o exercício, pelo povo, da soberania se funda na constituição de uma vontade geral, que é inalienável, indivisível e absoluta. Ela não é o

10 Cf. Locke, John. Traité sur le gouvernement civil. Paris, PUF,1951.

11 Cf. Montesquieu. De l'Esprit des lois. Paris, Classiques Garnier, 1973.

12 Cf. Ellul, Jacques. Histoire des Institutions (XVI-XVIII siècles). Paris, PUF, 1999.

13 Apud Ellul, Jacques, op. cit.

14 Cf. Baczko, Bronislaw. Rousseau, Rousseauismes. in ORY, Pascal (org.) Nouvelle histoire des idées politiques. Paris, Hachette, 1987. 
somatório das vontades individuais, nem a vontade de uma maioria, mas visa o interesse geral e o bem comum.

Quanto à vertente exógena da soberania, ela também é, em grande parte, preservada pelo Estado moderno ao longo de sua história, malgrado alguns esforços pontuais em contrário. Os helenos, outrora, já haviam concebido uma fórmula de compartilhamento de soberania, primeiro através das anfictionias ${ }^{15}$, depois, das ligas e confederações - como a amfictionia de Delpho, agrupando doze povos, a Liga de Delos, capitaneada por Atenas ou a Confederação Beociana, liderada por Tebas. Posteriormente, essa fórmula é revisitada, ao longo da Idade Média, com a Liga Hanseática ou a Confederação Helvética, por exemplo.

Durante a construção e consolidação do Estado moderno, o caráter externo absoluto da soberania - que legitima a guerra - é pontualmente atenuado. Hugo de Groot, em seu De jure belli ac pacis, esforça-se no sentido de estabelecer princípios regulatórios capazes de evitar conflitos bélicos. No mesmo sentido o Abbé de Saint-Pierre, autor do Projet de la paix perpetuelle, preconiza uma confederação de Estados europeus, o que inspira Immanuel Kant a redigir, quase um século mais tarde, obra homônima, que exerceria uma influência notável sobre o pensamento transnacionalista. Já no século XIX, Henri de Saint-Simon, através de sua monumental $D e$ la réorganisation de la Société européenne ou de la nécessité et des moyens de rassembler les peuples de l'Europe en un seul corps politique en conservant chacun son indépendance nationale, preconiza uma federação européia capaz de forjar um equilíbrio em um continente abalado pelas guerras revolucionárias e napoleônicas. Ele afirma que a Europa terá a melhor organização possível, se todas as nações que ela circunscreve, cada uma governada por um parlamento, reconhecerem a supremacia de um parlamento geral situado acima de todos os governos nacionais e revestido do poder de julgar seus contenciosos. Como sublinha Christophe Prochasson, "Saint Simon faz a aposta em que convém afastar-se da pátria para melhor retornar a ela"16.

Em suma, constata-se que o conceito de soberania no pensamento político ocidental se encontra atrelado à formação do Estado moderno. Entretanto, fica patente a influência da filosofia greco-latina e medieval em

15 Anfictionias: associações reunindo cidades gregas com o fito de celebrar cultos e ritos. Ela catalisa esforços de associação que desembocam, não raro, nas futuras ligas ou confederações. 16 Cf. Prochasson, Christophe. "L'Europe de Saint-Simon”. Le Monde des Débats, n 21, janvier 2001. 
alguns aspectos desse conceito. A concepção dualista contemporânea que assume a existência de duas categorias de contexto - o nacional e o internacional - deriva, de fato, de uma prática intelectual secular arrimada numa compreensão tomizada de soberania ${ }^{17}$. Inicialmente, e durante séculos, gregos e, depois, romanos praticam uma soberania mitigada que varia da cidade-estado interdependente a um império mosaico repleto de autonomias ${ }^{18}$. Posteriormente, durante os "mil anos de trevas", germina uma soberania dicotômica dividida entre os domínios espiritual e temporal.

Ora, o século XX, marcado por duas grandes guerras mundiais, pela consolidação de estados nacionais como a Alemanha de Bismark ou a Itália de Garibaldi, é também o século dos quartorze pontos de Woodrow Wilson, da SDN, da ONU e do Tratado de Roma. Ele reflete, no que concerne à soberania, a conjunção de um patrimônio histórico milenar oscilante com uma realidade conjuntural específica que solicita novas formas de entente entre os povos.

\section{DO FENÔMENO DE INTEGRAÇÃO REGIONAL}

O outrora todo poderoso Estado-nação soberano parece não mais responder, enquanto organização política ótima, à entente desejada pelos povos. A revolução telemática do último quartel do século passado precipita o fenômeno de interdependência, que se inicia após a queda das potências do Eixo, em uma dinâmica cada vez mais complexa. Norbert Elias indica que "em todo o mundo as tribos perdem sua função autônoma de unidades de sobrevivência (...). No atropelo da integração crescente numerosos estados perdem grande parte da sua soberania"19.

David Mitrany, em cima do fracasso da Sociedade das Nações, desenvolve o paradigma funcionalista, ancorando-o numa perspectiva utilitarista, onde o politico se acha subordinado ao técnico, e onde o Welfare State, sobrecarregado, transfere parcelas limitadas de sua competência a

17 Cf. Hermet, Guy, Badie, Bertrand, Birnbaum, Pierre, Braud, Philippe. Dictionnaire de la science politique et des institutions politiques. Paris, Armand Colin, 2000. Bobbio, Norberto. Dicionário de Política. Brasília, Editora da Unb, 1996.

18 "Quand en 410 parvint en Afrique la nouvelle, on ne voulut pas y croire : Rome pillée par Alaric, un chef wisigoth fédéré un temps avec l'Empire et qui s'est mis à son compte". Cf. Jerphagnon, Lucien. Préface à la Cité de Dieu, de Saint Augustin. Collection La Pléiade. Paris, Gallimard, 2000.

19 Cf. Elias, Norbert, op. cit. 
instituições transnacionais ${ }^{20}$. Paul Taylor assim resume o pensamento funcionalista de Mitrany :

"(Man) can be weaned away from his loyalty to the nation state by the experience of fruitful international cooperation; international organization arranged according to the requirements of the task (can) increase welfare rewards to individuals beyond the level obtainable within the state. Individuals and groups could begin to learn the benefits of cooperation... creating interdependencies (and) undermining the most important bases of the nation state"21. Mitrany inova, dessa maneira, lançando conjecturas sobre uma nova forma de gerenciamento do poder soberano.

No rastro de David Mitrany, Ernst Haas prolonga a reflexão sobre o funcionalismo, introduzindo a necessidade de criação de instituições supranacionais formais, aptas a enquadrar e estimular o spill over. Esse estímulo é perpetrado pela ação de um órgão dotado de supranacionalidade representativa, que no caso da União Européia é incarnado pela Comissão. Além disso, se as instituições comunitárias almejam uma dinâmica eficiente, elas devem aplicar o voto por maioria em seu processo de tomada de decisões. Haas define a integração como "the process whereby political actors in several distinct national settings are persuaded to shift their loyalties, expectations and political activities towards a new and larger center, whose institutions possess or demand jurisdiction over the pre-existing national states"22. Uma vez as instituições edificadas e o processo em marcha, a integração induz o declínio da soberania estatal, levando à sedimentação de um novo espaço público, de novas lealdades, de um novo imaginário socio-político.

Todavia, o impulso transnacionalista que marca os "trinta anos gloriosos" 23 reduz-se consideravelmente a partir do primeiro choque do petróleo em 1974. Igualmente, o paradigma europeu de integração sofre alguns revezes importantes, como a crise da "cadeira vazia" e o subse-

20 Cf. Mitrany, David, "The functional approach to world organization", International Affairs, 24 (1948).

${ }^{21}$ Apud Griffiths, Martin. Fifty Key Thinkers in International Relations. London, Routledge. 1999.

22 Cf. Haas, Ernst. "International integration: the European and the universal process". International Organisation, 15 (1961).

23 "Trinta anos gloriosos": período de crescimento forte e regular dos grandes países industriais de 1945 a 1974. Cf. Bezbbakh, Pierre, Gherardi, Sophie (org.).. Dictionnaire de l'Economie. Paris, Larousse/Le Monde, 2000. 
qüente "arranjo de Luxemburgo"24, que salientam as dificuldades de implementação dos princípios de integração. A integração regional não progride mais como imaginado, pois os diferentes Estados nela implicados se encontram atrelados a lógicas que ultrapassam a arena européia.

Verifica-se, então, um retorno parcial e gradual às premissas realistas, que se galvanizam através da noção de interdependência complexa concebida por Robert Keohane e Joseph Nye ${ }^{25}$. Eles constatam uma multiplicação das interações internacionais mas, ao mesmo tempo, observam que há uma distinção clara entre relações políticas - que incluem a possibilidade de recurso à força - e transnacionais - onde ao menos um dos atores presentes não é um agente governamental. Essas interações múltiplas se dividem em quatro categorias ${ }^{26}$ : informação, comércio de mercadorias, fluxos financeiros e livre circulação de pessoas e idéias. Introduzindo, posteriormente, os conceitos de sensitivity - medida a curto prazo - e vulnerability - medida a longo prazo - Keohane e Nye rompem com a dicotomia milenar entre política interna e externa ${ }^{27}$. A interpenetração crescente das atividades transforma a fronteira numa isóbara política mais permeável, onde processos osmóticos violam o hermetismo de outrora.

Há que se lembrar igualmente que, numa tentativa interpretativa menos estatocêntrica do cenário internacional dos anos sessenta, John Burton resgata os recursos desenvolvidos por Grotius, o Abbé de SaintPierre ou Kant para organisar a escola do mundialismo ${ }^{28}$. Burton substitui, então, a interpretação "bolas de sinuca" - fundada no power politics - pela concepção "teia de aranha" (cobweb) que tenta considerar as inúmeras transações que escapam a rigidez das fronteiras físicas. Como Keohane e Nye, ele refuta a distinção entre política interna e internacional, considerando a insatisfação das necessidades internas como sendo a causa das tensões mundiais.

24 "Cadeira vazia" (chaise vide): crise caracterizada pelo boicote da França, em 1965, às instituições comunitárias. "Arranjo de Luxemburgo": protocolo assinado, em 1966, entre os parceiros das Comunidades Européias para resolver a crise da cadeira vazia e que reforçava o princípio de tomada de decisão consensual. Cf. Quermonne, Jean-Louis. Le système politique de l'Union Européenne. Paris, Montchrestien, 2001.

25 Cf. Keohane, Robert; Nye, Joseph. Transnational Relations and World Politics. Harvard University Press, 1972.

26 Apud Roche, Jean-Jacques Théories des Relations Internationales. Paris, Montchrestien, 1997.

27 Cf. Keohane, Robert; Nye, Joseph. Power and Interdependence: World Politics in Transition. Boston, Little Brown, 1977.

${ }^{28}$ Cf. Burton, John. World Society. Cambridge University Press, 1972. 
É no mesmo rumo de John Burton que Norbert Elias constrói os postulados da sociedade dos indivíduos e debuta suas cogitações referentes à unidade de sobrevivência e ao habitus social. Ele utiliza a imagem de uma malha tecida com múltiplos fios, que se acham mutuamente interligados, de forma que nem o conjunto do sistema, nem cada um dos diferentes fios podem ser explicados a partir de um só ou de todos os diferentes fios, mas somente podem ser compreendidos a partir de suas associações e relações recíprocas. Essas relações criam um campo de forças que se propaga entre cada um dos fios segundo a posição e função de cada um deles no seio da rede. A forma de um fio se modifica quando a tensão e a estrutura do conjunto do sistema se metamorfoseia. E, portanto, essa malha não é outra coisa senão a reunião de diferentes fios, mesmo se, paralelamente, cada fio constitui no interior desse conjunto uma unidade em si, ocupando, aí, um lugar particular e revestindo-se de uma forma específica ${ }^{29}$.

Em oposição a um habitus social centrado no Estado nacional, Elias sugere um outro, forjado em cima de elementos que fazem parte das realidades da existência social atual. Se essa existência estrutura-se primitivamente a nível de integração do clã e das tribos, passando, posteriormente, pela integração a nível do Estado-nação, hoje ela se baseia numa unidade de sobrevivência que vai além das fronteiras nacionais. Norbert Elias estima que "unidades sociais de maior porte retomaram a função principal de sobrevivência das unidades menores. O processo não precisa desenrolar-se na mesma direção. Mas não é impossível que o faça. A transmissão da função de unidade principal de sobrevivência a unidades sociais que representam um nível de integração superior regularmente produziu defasagens. (...) Reproduziu-se sempre a mesma cisão entre a retomada de fato da função de unidade principal de sobrevivência por unidades sociais de nível superior de integração e a fixação tenaz da identidade dos indivíduos às unidades de um estágio anterior" ${ }^{30}$. Assim, ele sugere que a unidade de sobrevivência atual reside na conformação de espaços integrados de regulação, sendo esses espaços apenas elos de uma malha global.

A integração regional se ergue, então, na intenção de atenuar uma dupla defasagem. Primeiro, aquela entre o econômico e o político, através da constituição de um poder soberano supranacional capaz de impor limites à lógica global, mercantil e financeira do livre mercado. Segundo, a defasagem

${ }^{29}$ Cf. Elias, Norbert, op.cit.

30 Ibid. 
entre, de um lado, o político-econômico e, de outro, o social, através da criação de um habitus apto a organizar novas práticas, atitudes e anseios do homem do terceiro milênio. Ela se constrói, assim, numa tentativa de interferir na lógica da international governance, caracterizada pela imbricação complexa de regimes múltiplos ${ }^{31}$. Esses regimes, segundo Stephen Krasner, definem mecanismos de autoregulação que reduzem a margem de manobra dos estados-nação, introduzindo dispositivos de ajustamento entre as políticas nacionais e as contingências internacionais à margem de todo arcabouço institucional ${ }^{32}$. A integração regional tenta, na verdade, racionalizar as relações entre o Estado e a sociedade, otimizando os modos de coordenação entre a concepção e a implementação da ação pública ${ }^{33}$.

A União Européia tenta cristalizar, a partir da segunda metade do século $\mathrm{XX}$, esforços pioneiros no sentido de se reapropriar da utopia transnacionalista que marca a história das relações internacionais. Com as mentes ainda profundamente impregnadas pelos horrores da Segunda Guerra Mundial, divisando num horizonte próximo a ameaça da Guerra Fria e desejando establecer meios que possam impedir a eclosão de novo conflito bélico, os tomadores de decisão da Europa Ocidental se resignam a conceber um processo institucional de integração regional calcado num exercício de soberania dividida.

Oscilando entre uma estratégia de cooperação - ancorada em práticas intergovernamentais e tomada consensual de decisão - e uma estratégia de integração - assentada em práticas surpranacionais e tomada de decisão por maioria - Alemanha, Bélgica, França, Itália, Luxemburgo e Países Baixos galgam os degraus da CECA (Tratado de Paris - 1951), CEE (Tratado de Roma - 1957), chegando, já com o concurso de outros parceiros, à União Européia (Tratado de Maastricht - 1993). Embora inúmeras crises tenham marcado o percurso dos Estados europeus, a experiência integracionista sobrevive enquanto alternativa viável, como demonstram as ainda recentes cimeiras de Amsterdã (1997) e de Nice (2000).

Se ela hesita entre se aprofundar e se alargar, a UE deve ainda enfrentar o dilema entre optar por um modelo neoliberal ou um outro mais

31 Para uma análise epistemológica e ontológica consistente dos regimes internacionais, ver Ruggie, John Gerard. Constructing the World Polity. London, Routledge, 1998.

32 Cf. Krasner, Stephen. Regimes and the Limits of Realism : Regimes as Autonomous Variables. in Krasner, Stephen (ed.), International Regimes. Ithaca, Cornell University Press, 1983.

33 Cf. Kooiman, Jan. Modern Governance. New Government-Society Interactions. London, Sage, 1993. 
intervencionista, capaz de efetuar mais expeditamente a função de redistribuição. Sem embargo, não se pode ocultar que, desde os primórdios, um dos principais objetivos da União Européia se constitui em promover uma redução entre os diferentes níveis de desenvolvimento entre países e/ou regiões intra-nacionais. A idéia é aproximar o nível de vida do cidadão das periferias daquela do cidadão dos centros mais desenvolvidos.

Por outro lado, filho de uma outra época e respondendo a demandas culturais e de desenvolvimento político distintas daquelas que selam o destino da União Européia, o Mercosul tenta, à sua maneira, não somente fornecer uma alternativa concreta aos desafios de reforma de seus Estadosmembros, mas também criar uma opção realista no que concerne às suas respectivas inserções internacionais. Ora, o processo de gênese do Mercado Comum do Sul situa-se num cenário de profunda metamorfose tecnológica onde as variáveis espaço, velocidade e tempo passam a ser definidas em função de novos parâmetros, determinados pela celeridade e precisão da lógica binária da informática. O corolário político de tal metamorfose reflete-se ipso facto na transformação da noção de fronteira, que assume um formato bem mais permeável, favorecendo uma interdependência osmótica. Essa interdependência se manifestando claramente nos setores financeiro, mercantil, cultural e social.

Todavia, o lastro onde repousa as fundações mercosulinas é marcado pela vontade recíproca de Argentina e Brasil de arrimar seus respectivos processos incipientes de redemocratização num espaço exógeno de regulação política visando a incrementar o nível de irreversibilidade de tais processos. Além disso, tenta-se ancorar as transformações econômicas do Estado e sua projeção estratégica internacional num patamar intermediário cujas premissas de funcionamento respondam às novas categorias de demandas planetárias: eficiência, rapidez, prática cidadã e preservação ecológica. Assim, contrariamente à UE, há que se verificar que a centralidade da ação dos parceiros mercosulinos encontra-se calcada em fatores que diferem daqueles que, outrora, fundaram o processo europeu de integração. De fato, não existe no Cone Sul um pretérito pontuado de guerras ${ }^{34}$, nem um cenário de possível conflagração armada quando do início das negociações entre Brasília e Buenos Aires em meados dos anos oitenta. A sobrevivência estatal não se encontra iminentemente ameaçada, nem assombra sociedades civis ou elites políticas atrocidades recentes e sistemáticas entre os povos de seus países.

34 Guerra Franco-Prussiana (1870), Primeira Guerra Mundial (1914) e Segunda Guerra Mundial (1939). 
A construção do Mercosul é lançada, pois, numa conjuntura psicológica que não concebe a possibilidade de um exercício de soberania dividida. A supranacionalidade introduzida na arena européia pela Alta Autoridade da CECA não encontra paralelo nem no cenário da integração latino-americana, em geral, nem no do Mercado Comum do Sul, em particular. O Estado-nação da América meridional parece, devido talvez à sua idade precoce e a um ranço colonialista ainda recente, fortemente ligado à prática clássica da soberania ${ }^{35}$. Assim, o movimento pendular entre a estratégia de integração e a de cooperação identificada ao longo da edificação da UE restringe-se, no Mercosul, a uma lógica retilínea que se pode qualificar de enquadramento da cooperação intergovernamental ${ }^{36}$.

Trata-se, na verdade, de um modus operandi específico que vai além de uma simples cooperação, mas que resta aquém de uma verdadeira dinâmica de integração. Em outros termos, preserva-se uma estrutura institucional inteiramente intergovernamental do ponto de vista político, mas gera-se uma prática reguladora a nivel econômico e social capaz de produzir rugosidades, elas próprias origem de momentum político com viés supranacional. Esssas rugosidades se galvanizam não somente através de uma produção normativa derivada - decisões, resoluções e diretrizes - mas igualmente pelo aparecimento progressivo de uma sociedade civil incipiente.

Apesar das inúmeras dificuldades no procedimento de internalização do direito oriundo do Tratado de Assunção e do Protocolo de Ouro Preto, as decisões, resoluções e diretrizes começam, pouco a pouco, a balizar as atividades dos cidadãos do Mercosul. A primazia desse balizamento concerne essencialemente as atividades de cunho mercantil, mas alguns outros setores, como o da educação, o da cultura ou, ainda, o do desenvolvimento regional começam também a ser contemplados ${ }^{37}$.

Quanto a uma sociedade civil mercosulina emergente, ela deve ser concebida como ainda extremamente frágil, posto que tracionada simultaneamente pelos processos antagônicos de globalização econômica e fragmentação cultural ${ }^{38}$. Esse embrião societal ainda não produz espaço

35 Cf. Césaire, Aimé, Et les chiens se taisaient. Paris, Présence Africaine, 1956.

36 Cf. Medeiros, Marcelo de A. La genèse du Mercosud. Paris, L'Harmattan, 2000.

37 Por exemplo : Decisão 09/91 criando as reuniões especializadas de turismo, ciência e tecnologia, cultura e meio-ambiente; Decisão 07/92 instaurando o Plano Trienal de Educação; Decisão 37/93 criando uma comissão ad hoc para o desenvolvimento regional; Decisão 38/93 concebendo um grupo ad hoc para estudar a confecção de um documento único de identificação aos quatro países.

${ }^{38}$ Cf. Huntington, Samuel. Le choc des civilisations., Paris, Odile Jacob, 1997. 
público no sentido evocado por Jürgen Habermas ${ }^{39}$, mas pode-se apontar cinco elementos que pleiteiam sua existência: os partidos políticos, a opinião pública, os grupos de interesse e de pressão, os movimentos regionais e as Forças Armadas ${ }^{40}$. É notório que a centralidade mercantil de outrora, embora continue robusta, começa a suscitar um fenômeno de contaminação que se alastra em diversos espaços das sociedades nacionais.

Contudo, a exemplo da UE, o processo de reificação do Mercosul padece, e de maneira crônica, de chagas relacionadas não somente às assimetrias entre os Estados-nações mas também atreladas às suas respectivas desigualdades intra-regionais. $\mathrm{O}$ desafio é, pois, pensar um formato institucional capaz de reger as relações entre parceiros e, sobretudo, apto a promover a coesão social e o desenvolvimento estrutural das unidades subnacionais que os compõem. É mister implementar uma lógica distributiva que possa aproximar as periferias dos centros e aplainar as divergências de interesses que, quase sempre, marcam suas relações.

\section{DA MULTITUDE DE PERIFERIAS}

O Tratado de Roma cria, como um de seus principais instrumentos de redistribuição, os Fundos Estruturais. Através do Fundo Social Europeu (FSE), Fundo Europeu de Desenvolvimento Regional (FEDER) e Fundo Europeu de Orientação e Garantia Agrícola (FEOGA), a UE se dota de instrumentos para implementar uma política de coesão econômica e social $^{41}$. Esses fundos representam em torno de $40 \%$ de suas despesas totais e visam a "reduzir o hiato entre os níveis de desenvolvimento das diversas regiões e o atraso das regiões ou ilhas menos favorecidas, incluindo as zonas rurais" 42 . Submetida a alargamentos sucessivos, a UE incorpora, progressivamente, novas regiões retardadas socio-economicamente é o caso das adesões da Irlanda, Grécia, Espanha e Portugal. Ao lado, porém, dessas macro-periferias continentais imediatas - sem esquecer os bolsos de subdesenvolvimento interiores aos quatro grandes (Alemanha, França, Itália e Reino Unido) - a União Européia deve considerar uma ultraperiferia longínqua, a qual grupa os Départements Français d'Outre

39 Cf. Quermonne, Jean-Louis, op. cit.

40 Cf. Medeiros, Marcelo de A., op. cit.

41 Cf. Quermonne, Jean-Louis, op. cit.

$42 \mathrm{C}$. Artigo 158 do Tratado de Amsterdã. 
Mer - DOM (Guadeloupe, Guyane, Martinique, Réunion), os arquipélagos portugueses dos Açores e da Madeira e as Canárias espanholas (todos partes integrantes dos respectivos espaços aduaneiros nacionais e, conseqüentemente, do da União Européia).

Ora, essa dinâmica de redistribuição dos Fundos Estruturais da UE conta, para o ano 2000, com um orçamento de quase 40 bilhões, sem considerar a soma, grosso modo semelhante, destinada à aplicação da Política Agrícola Comum (PAC) ${ }^{43}$. Na verdade, equipada com um sistema de captação de recursos que é independente da vontade política dos Estados-membros, a UE outorga a seu sistema institucional e a sua prática social uma legitimidade concreta, e transforma a Comissão Européia num ator redistributivo integral no cenário integracionista do velho continente ${ }^{44}$.

O Mercado Comum do Sul, por sua vez, sofre com a ausência de um orçamento próprio. Somente a Secretaria Administrativa conta com um orçamento logístico de funcionamento que é financiado em partes iguais por contribuições dos Estados-membros que, aliás, quase sempre estão atrasados em suas doações ${ }^{45}$. Porém, numa atitude que pode induzir a se pensar na constituição de um fundo comum voltado para o desenvolvimento, o Protocolo de Ouro Preto, em seu preâmbulo, aponta "para a necessidade de uma consideração especial para países e regiões menos desenvolvidos do Mercosul".

Sem embargo, as heterogeneidades no quadro do Cone Sul são gritantes e de duas ordens. Em primeiro lugar, há que se constatar um desnível abissal entre as unidades formadoras do Mercosul, o Brasil representando, grosso modo, 2/3 da população, do PIB e do território do conjunto integracionista ${ }^{46}$. Tomando-se o tandem Brasil \& Argentina a proporção é ainda mais significativa, representando em torno de $95 \%$ dos indicadores supracitados. Logo, Paraguai e Uruguai surgem como Estados satélites que gravitam em torno dos interesses do eixo Brasília-Buenos Aires.

43 Cf. Leparmentier, Arnaud. "La révolution agricole allemande se heurte aux réalités du marché". Le Monde, 28/01/01, p. 03.

44 De maneira geral, as fontes de recursos próprios da UE provém: de 1,4\% do imposto de valor agregado cobrado pelos Estados-membros ( $₫ 32,5$ bilhões em 2000); e de porcentagem da tarifa externa comum aplicada pelos Estados-membros a terceiros países ( $\propto 12,3$ bilhões em 2000). Cf. Quermonne, Jean-Louis, op. cit.

45 Cf. Artigo 45 do Protocolo de Ouro Preto.

46 Argentina: 2.766.889 Km2, 36,6 milhões de habitantes e US\$ 434 bilhões de PIB; Brasil: 8.511.965 Km2, 168 milhões de habitantes e US\$ 1,1 trilhão de PIB; Paraguai: 406.752 Km2, 5,4 milhões de habitantes e US\$ 22,4 bilhões de PIB; Uruguai: $176.215 \mathrm{Km} 2,3,3$ milhões de habitantes e US\$ 28,4 bilhões. Cf. L'Etat du Monde, La Découverte, Paris, 2001. 
Em segundo lugar, pode-se verificar as heterogeneidades subnacionais que, infelizmente se mostram de mesma magnitude. Assim, no seio da República Federativa do Brasil apenas três estados federados, Minas Gerais (15\%), Rio de Janeiro (15\%) e São Paulo (35\%) $)^{47}$, detêm, aproximadamente, $65 \%$ do PIB nacional, concentrando o essencial do parque industrial e de seviços. Sua região Nordeste ${ }^{48}$, inversamente, revela-se um verdadeiro celeiro de pobreza e subdesenvolvimento, cuja economia ainda se baseia na produção de comodities ou de bens com baixo valor agregado. Em 1994, por exemplo 93\% de todas as exportações do Brasil para o Mercosul são realizadas pelos estados das regiões Sul ${ }^{49}$ e Sudeste, cabendo a São Paulo sozinho, uma contribuição de mais de 54\%, seguido pelo Rio Grande do Sul, com participação em torno de 10\%. As regiões Nordeste, Norte e Centro-Oeste, nesse mesmo ano, contribuem com apenas $7 \%$ das exportações brasileiras para os parceiros mercosulinos ${ }^{50}$. Isso não impede, portanto, que as exportações do Nordeste para o Mercado Comum do Sul passem de 3,21\% em 1990 a 9,56\% em 1994, mesmo se sua participação no total das exportações brasileiras rumo ao Mercosul regridem de 7,53\% a 5,53\% no mesmo período ${ }^{51}$.

A concentração de riqueza e de poder na República Argentina não é menos importante. A hegemonia portenha se exerce, na realidade, tanto na esfera política - através de um federalismo centralista - quanto na arena econômica - através de uma concentração produtiva de bens e seviços na capital federal. Contrariamente ao Brasil, onde ao polígono econômico São Paulo-Rio de Janeiro-Minas Gerais se contrapõe o bastião político de Brasília, Buenos Aires acumula, pari passu, poder político e potência econômica, gerando uma situação de quasi-monopólio dificilmente contestável pelas demais Províncias. Se centros como Córdoba ou Rosário ainda conseguem avançar na sombra bonairense, a situação difere em unidades subnacionais como Salta, no Nordeste argentino, onde recessão e

47 Esses três estados formam a Região Sudeste.

48 Formada pelos estados de Alagoas, Bahia, Ceará, Maranhão, Paraíba, Pernambuco, Piauí, Rio Grande do Norte e Sergipe, representando 18,3\% do território nacional.

49 A Região Sul é formada pelos estados do Paraná, Rio Grande do Sul e Santa Catarina.

50 Cf. Arrouxelas Galvão, Olímpio José (de), "Tendências recentes do comércio internacional: impactos sobre o Brasil e a Região Nordeste", in Comércio internacional e o Mercosul: impactos sobre o Nordeste brasileiro. Fortaleza, Banco do Nordeste do Brasil, 1997.

51 Cf. Portela, Aloísio. "Mercosul vai prejudicar o NE". Diário de Pernambuco, 08/10/95. 
desemprego atingem níveis abissais. Nesta Província $60 \%$ da população vivem na pobreza e $17 \%$ na indigência total ${ }^{52}$.

Além dessas duas ordens de disparidade - extra e intra-nacionais - há que se recordar que União Européia e Mercosul pertencem a categorias de integração distintas, a primeira almejando a integração de países desenvolvidos, o segundo aspirando à colaboração entre nações em vias de desenvolvimento ${ }^{53}$. Ora, esta realidade sublinha o caráter intrínseco da marginalidade do Mercosul no cenário internacional. Com um PIB em torno US\$ 1,6 trilhões, população de, grosso modo, 220 milhões de habitantes e participação no comércio mundial de apenas $1,66 \%$ (em 1997) ${ }^{54}$, o Mercado Comum do Sul difere sensivelmente da UE ou do NAFTA ${ }^{55}$. Ou seja, esses dois conjuntos regionais centrais e estrategicamente mais influentes possuem uma capacidade de redistribuição obviamente mais eficaz, na medida em que detêm riqueza superior àquela de conjuntos regionais periféricos como o Mercosul, a Comunidade Andina ou a SADC ${ }^{56}$. Além disso, no caso específico da União Européia, mecanismos supranacionais facilitam a tarefa de redistribuição, tão dificilmente gerenciáveis num quadro puramente intergovernamental.

Pode-se, assim, conceber uma grade de leitura das múltiplas formas de periferias que, às vezes assumem posições excludentes, mas às vezes posturas includentes. Nesse último caso constata-se uma surperposição de periferias, gerando um efeito cascata de forma concêntrica que se revela de natureza nefasta. Seguindo essa lógica, propõe-se uma taxonomia em quatro níveis:

macro-periferias: quando os próprios espaços de integração constituem uma zona marginal no seio do sistema internacional (Mercosul, $\mathrm{MCCA}^{57}$, SADC, etc.);

meso-periferias: quando no quadro de um processo de integração regional encontram-se estados-membros inteiros em situação de atraso (México no NAFTA, Paraguai no Mercosul, Irlanda na UE, etc.);

micro-periferias: na medida em que unidades subnacionais se revelam abaixo da média do conjunto integracionista (Região Nord-Pas-

52 Cf. Leser, Eric. "L'Argentine tente de sortir de la crise". Le Monde, 22/06/01.

53 Cf. Grugel, Jean, Hout, Wil (eds.), Regionalism Across the North-South Divide : State Strategies and Globalization. London, Routledge, 1999.

${ }_{55} C f$. Página web do Ministério das Relações Exteriores do Brasil: www.mercosul.gov.br

55 NAFTA: North American Free Trade Agreement.

56 SADC: Southern African Development Community.

57 MCCA: Mercado Comum Centro Americano. 
de-Calais no Norte da França, a Calábria ou a Campania no Sul da Itália); ultra-periferia: quando regiões se encontram profundamente retardadas em relação às médias nacionais e/ou comunitárias (DOM franceses, Açores, Madeira, Canárias, Patagônia argentina ou o Nordeste brasileiro).

De acordo com essa grade, a região do Chaco paraguaio, por exemplo, ilustraria a supracitada dinâmica de surpeposição de marginalidades. Na verdade ela é simultaneamente ultra-periferia, meso-periferia e macro-periferia, pois se trata de região com profundo retardo em relação às médias nacionais, é parte de Estado-membro relativamente menos desenvolvido em relação aos parâmetros comunitários (Paraguai) e, finalmente, é elemento constitutivo de um processo de integração periférico (Mercosul).

Atualmente com quinze membros, a UE, vista à luz da grade aqui proposto, apresenta sobretudo micro-periferias. Suas meso-periferias têm se atenuado nas últimas duas décadas com o desenvolvimento contínuo da Espanha, da Grécia, da Irlanda e de Portugal. Claro está que o processo de alargamento rumo ao Leste, ora em curso, deve modificar essa paisagem política, na medida em que ele poderá provocar a adesão de Estados que são, quase que como um todo, atrasados em relação à média comunitária. Será um retorno às meso-periferias.

Sem embargo, esse retorno tem se mostrado um desafio-mor para as reformas institucionais visando ao alargamento da UE, pois trata-se de se repensar os instrumentos e critérios de redistribuição numa lógica de decréscimo relativo de recursos. Segundo cálculos da Comissão Européia ${ }^{58}$ a adesão da Estônia, Letônia, Lituânia, Polônia, República Checa, Eslováquia, Hungria, Eslovênia, Romênia, Bulgária e Chipre aumentará de $34 \%$ a massa geográfica e de $29 \%$ a população da UE, enquanto que seu PIB só crescerá de 5\%. As meso-periferias de ontem - Espanha, Portugal, Grécia e Irlanda - adotam, então, uma atitude refratária face às meso-periferias atuais e tentam obter garantias do poder supranacional comunitário gerenciador dos Fundos Estruturais, que sejam capazes de preservar um mínimo de benefícios. Essa posição tende, evidentemente, a retardar o andamento das negociações entre os Quinze e os PECO $^{59}$. Todavia, interesses de ordem política, comercial e financeira atenuam a posiçao das exmeso-periferias, levando-as, globalmente, a se alinhar com a visões da "maioria" da UE e do poder supranacional da Comissão.

58 Cf. "A Survey of European Enlargement". The Economist, May 19th 2001.

59 PECO: Países da Europa Central e Oriental. 
Não obstante a supremacia decisória do Conselho de Ministros, a constelação de instituições suprancionais, que germina na paisagem política da Europa comunitária, revela-se uma aliada preciosa no sentido de sedimentar as práticas sociais, políticas e econômicas no espaço público da UE e, por conseguinte, gerenciar mais racional e democraticamente o problema das periferias e a questão da lógica distributiva dos ganhos. Esse não é o caso de figura do Mercado Comum do Sul, que ainda resta tributário de uma dinâmica por demais intergovernamental, mesmo se incarnando uma vontade manifesta de inserção internacional geradora, ao menos a curto prazo, de marginalidades múltiplas.

\section{DA LÓGICA DISTRIBUTIVA}

A simultaneidade dos processos de globalização, regionalização e fragmentação exige, pois, dos Estados-nações, uma grande capacidade de adaptação. É mister conciliar eficácia e democracia, fatores constitutivos do tempo mundial ${ }^{60}$ pós-guerra fria e associação quasi-consensual para as comunidades epistêmicas ${ }^{61}$. Democracia não somente no sentido formal ou institucional, "como o nome pomposo de alguma coisa que não existe"62 , porém em sua acepção primeira, como "uma associação onde o livre desenvolvimento de cada um é a condição para o livre desenvolvimento de todos"63. A interdependência econômica de facto entre unidades parceiras deve ser traduzida por uma solidariedade social de jure, fundada em lógica distributiva consistente e apta a estabelecer um arcabouço político estável e duradouro.

É preciso notar, contudo, que a noção de distribuição vai além da simples transferência de fundos - ação situada a jusante. Ela também é marcada pela capacidade dos diversos níveis de unidades formadoras do

60 Tempo mundial: confluência do fenômeno político - caracterizado pela queda do regime soviético; e do fenômeno econômico - marcado pela globalização de fluxos comerciais e financeiros. Gera-se, assim, um quasi-consensus em torno do binômio democracia de mercado.Cf. Laïdi, Zaki. L'Ordre mondial relâché: sens et puissance après la Guerre Froide. Paris, PFNSP, 1993.

61 Cf. Haas, Peter. "Epistemic Communities and International Policy Coordination". International Organization 46 (special issue):1, 1992.

62 Cf. Sartori, Giovanni. Théorie de la démocratie. Paris, Armand Colin, 1973.

63 Cf. Marx, Karl, Engels, Friedrich. Manifeste du Parti Communiste (1848). Apud Hermet, Guy; Badie, Bertrand; Birnbaum, Pierre; Braud, Philippe. Dictionnaire de la science politique et des institutions politiques. Paris, Armand Colin, 2000. 
todo comunitário de influenciar a definição de prioridades estratégicas e de aumentar suas capacidades de participação na concepção e implementação de políticas públicas - ação situada a montante. Principalmente no que concerne as unidades mais marginalizadas. Trata-se, dessa maneira, de uma redistribuição de competências. Logo, na medida em que os processos de regionalização induzem a criação de novas lealdades e de novos espaços de regulação, impõe-se que algumas prerrogativas estatais também se desloquem na direção de um poder supranacional, transformando-o em depositário da vontade coletiva e árbitro da lógica distributiva comunitária.

Nesse sentido, pode-se identificar, lato sensu, três modalidades de supranacionalidade no contexto da integração regional:

Supranacionalidade de proposição: é exercida por órgão cujos membros representam o conjunto comunitário e não os Estadosmembros aos quais pertencem. Esse colégio assume, quase que exclusivamente e segundo as grandes orientações dos Estadosnacionais, a tarefa de conceber o arsenal normativo que baliza o processo de institucionalização e as práticas sociais. Trata-se do primeiro degrau rumo à supranacionalidade plena;

Supranacionalidade de controle: é assumida por ente institucional independente dos Estados-membros, cuja função é de velar pela aplicação uniforme da produção jurídica do conjunto comunitário, e isto através da criação de uma jurisprudência interpretativa unívoca e inapelável. Constitui-se em estágio intermediário e em exercício de maturação em direção a uma supranacionalidade detentora de soberania;

Supranacionalidade de decisão: é encarnada por uma prática fundada no voto por maioria qualificada que, ele próprio, encerra o real poder soberano de tomada de decisão. Adotada paulatinamente, ela restringe-se, num primeiro tempo, a setores específicos do processo de integração, após o que inicia um movimento progressivo de contaminação - spill over. Inversamente às supranacionalidades de proposição e de controle - intrinsicamente vinculadas à existência de corpos supranacionais de representação, sem contudo constituir fontes primárias e soberanas de poder - a supranacionalidade de decisão tem se acomodado a dispositivos intergovernamentais que, todavia, tem conseguido galvanizar o exercício da soberania no espaço comunitário.

Ora, à luz dessa grade de interpretação, percebe-se que, enquanto na União Européia a existência simultânea das três modalidades de 
supranacionalidade é verificada - como a Comissão Européia, a Corte de Justiça e o Conselho de Ministros - no Mercado Comum do Sul elas são inexistentes. Apenas a Secretaria Administrativa do Mercosul, órgão eminentemente de apoio logístico, é caracterizada por uma supranacionalidade de representação. Os membros do Grupo Mercado Comum (GMC) estando hierarquicamente submetidos aos seus superiores do Conselho Mercado Comum (CMC) elaboram proposições que tendem a proteger os interesses nacionais e, portanto, não assumem os interesses comunitários. Por outro lado, o CMC, o GMC e a Comissão de Comércio aplicam a regra do voto consensual - com a presença de todos os Estados-membros - nas suas tomadas de decisão, distanciando-se pois da via majoritária64. Enfim, a dinâmica ad hoc do Protocolo de Brasília de solução de controvérsias não induz à perenidade jurisprudencial de um Tribunal supranacional, elemento, não raro, requisitado pelos atores políticos, sociais ou agentes econômicos enquanto garantia de suas futuras ações.

Pode-se assim constatar que, no caso mercosulino, a lógica distributiva permanece prerrogativa exclusiva do Estado-nação, posto que o processo de integração regional não gera nenhum mecanismo concreto de compensação ou de transferência de competências em direção de instituições supranacionais. $\mathrm{Na}$ verdade, estas simplesmente não existem. É verdade que a criação do Forum Consultivo Econômico e Social pelo Protocolo de Ouro Preto, assim como o engajamento mais explícito da Comissão Parlamentar Conjunta, procuram atenuar o estato-centrismo que tem guiado o processo integrationista do Cone Sul. Também dinâmicas mais informais, como a da rede Crecenea/Codesul e aquela das Mercocidades, têm tentado influenciar o modus vivendi do Mercosul no sentido de intensificar sua democratização através de uma participação mais efetiva das unidades subnacionais ${ }^{65}$.

No caso da UE, além da tríade Comissão, Corte de Justiça e Conselho de Ministros - que reproduzem, respectivamente, supranacionalidades de proposição, de controle e de decisão - outras instâncias interferem

64 Cf. Art. 37 do Protocolo de Ouro Preto.

65 Crecenea: Comissão Regional de Comércio Exterior do Nordeste Argentino; Codesul: Conselho de Desenvolvimento e Integração Sul. A rede Crecenea/Codesul reune duas vezes por ano, a partir de 1995, os Governadores das províncias do Nordeste Argentino e dos estados do Sul e Centro-oeste brasileiros. Esta cimeira vai bem além de desafios meramente administrativos e constitui um ato político no qual as províncias e estados federados prolamam a importância de seus papéis no processo de integração do Mercosul. A rede de Mercocidades reúne cidades do Mercosul e do Chile com o objetivo principal de promover a participação cidadã. $C f$. Medeiros, Marcelo de A. La genèse du Mercosud. Paris, L'Harmattan, 2000. 
no procedimento distributivo comunitário66. Entre elas destacam-se o Comitê Econômico e Social (CES) e o Comitê de Regiões (CR) que vão tentar, apesar de seus papéis meramente consultivos, exprimir, respectivamente, os interesses de segmentos socio-econômicos e de unidades infraestatais junto aos poderes supranacionais de decisão. Se por um lado o CES estrutura-se em torno da noção de interesses de grupos econômicos e societais dos mais diversos horizontes comunitários, por outro lado o CR reificase segundo uma lógica geográfica, congregando unidades subnacionais que, algumas vezes, sentem-se excluídas do processo integrativo. Paradoxalmente, esse sentimento de exclusão manifesta-se ora pela fraqueza estratégica da unidade infra-estatal, que tenta então se fazer ouvir pelas autoridades supranacionais; ora pela robustez de algumas delas, que consideram restritos seus espaços de ação dentro do quadro do Estado-nação.

Malgrado o objetivo comum de atenuar a forte presença do Executivo central nas negociações comunitárias, essa contradição intrínseca dificulta o funcionamento do Comitê de Regiões, na medida em que a heterogeneidade profunda entre suas partes constitutivas dificulta as relações horizontais e a definição de novos parâmetros de equlíbrio do todo integracionista. Assim algumas pequenas unidades ${ }^{67}$ que têm assento no $\mathrm{CR}$ receiam que entes como o Land Baden-Wurtemberg (Alemanha) ou Regiões como a Catalunha (Espanha), Lombardia (Itália) ou Rhône-Alpes (França) fagocitem seus interesses, impondo, pois, suas próprias visões de desenvolvimento dentro da $\mathrm{UE}^{68}$. Donde o intenso apego das pequenas unidades subnacionais aos laços protetores do Estado-nação e a decepção das unidades mais desenvolvidas no que concerne uma maior autonomia e uma ação mais direta junto às autoridades supranacionais de Bruxelas.

O cruzamento das funções do CES e do CR acarreta uma complementaridade salutar no que se refere à formação de uma compreensão não

66 É verdade que desde a introdução do mecanismo de Codecisão pelo Tratado de Maastricht (art. 251 TCE, ex-189 B), o Parlamento Europeu vem assumindo, progressivamente, um papel importante, tentando responder assim ao déficit democrático que tem permeado o processo de integração da UE. Através desse procedimento o Parlamento detem um verdadeiro poder de veto, adquirindo, assim, um poder de decisão. O Parlamento Europeu também dispõe de um poder indireto de proposição, ou seja, ele pode submeter à Comissão proposições de elaboração de normas comunitárias. $C f$. Quermonne, Jean-Louis. Le système politique de l'Union Européenne. Paris, Montchrestien, 2001.

67 Como a Presidência da Câmara Municipal de Sintra e a Presidência do Governo da Região Autônoma dos Açores (Portugal) ou ainda o Alcade de Langreo (Espanha).

68 Cf. Balme, Richard (sous la direction de). Les politiques du néo-régionalisme. Paris, Economica, 1996. 
monolítica da integração européia, ou seja, que a percebe não apenas como uma simples relação entre Estados-nações, mas como um sistema imbricado de convívio de interesses entre sociedade civil e agentes econômicos ${ }^{69}$. Esses interesses são canalisados pelos diversos níveis de administração, gerando uma prática que alguns estudiosos tem denominado governance $e^{70}$. Sem embargo, é a capacidade de mobilização que pontua o fenômeno de governance que exerce uma forte influência na transformação da lógica distributiva em suas duas vertentes, a saber: a montante e a jusante.

Dotada de dispositivos supranacionais de todas as naturezas, a União Européia, apesar da complexidade de seu funcionamento, parece constituir um genuíno espaço de regulação política, social e econômica ${ }^{71}$. Ora, é essa regulação que proporciona a implementação e, em seguida, o reforço da lógica distributiva, cristalizando-a como resultante da combinação dos esforços do poder supranacional comunitário e das unidades infra-estatais, por um lado, e do Estado-nação, por outro. Todavia, é o poder supranacional comunitário que, organicamente, funciona como um verdadeiro catalisador de tal processo. Desprovido do arsenal supranacional que marca a integração européia, o Mercado Comum do Sul regula, naturalmente, menos e, até o momento, tem concentrado essa regulação essencialmente ao setor mercantil. A frágil mobilização, consequiência do baixo capital social 72 dos Estados-membros, dificulta, intra muros, o desenvolvimento da fórmula da governance, agravando as deficiências de redistribuição inerentes, lato sensu, a toda oganização política de integração que almeja sobreviver coerentemente num cenário internacional globalizado.

69 Esta é, lato sensu, a linha de pensamento de Moravcsik. Segundo ela haveria três etapas na discussão de um acordo de integração: (i) a formação de preferências nacionais, (ii) as negociações inter-estatais e (iii) a escolha institucional. Cf. Moravcsik, Andrew, Integrating International and Domestic Theories of International Bargaining. in Evans, Peter; Jacobson, Harold; Putnam, Robert (eds.) International Bargaining and Domestic Politics: DoubleEdged Diplomacy. Berkeley, University of California Press, 1993.

70 Utiliza-se aqui a definição de governança elaborada por Hocking e Wallace: "whilst government rests on formal authority and ultimately, the capacity to coerce, governance suggests a combination of both governmental and non-governmental mechanisms resting on shared goals and relying on consensus rather than coercion". $C f$. Hocking, Brian, Wallace, William. Multi-level Governance: an Overview. Paper apresentado no workshop "Regional Integration and Multi-level Governance", do European Consortium for Political Research - ECPR. Berna, 27 de fevereiro / 04 de março de 1997.

71 Mesmo se em graus diferenciados: regulação econômica > regulação política > regulação social. Cf. Scharpf, Fritz. Gouverner l'Europe. Paris, Presses de ScPo, 2000.

72 Cf. Putnam, Robert. Making Democracy Work: Civic Tradition in Modern Italy. Princeton University Press, 1993. 


\section{CONCLUSÃO}

A noção de soberania que reside no imaginário ocidental encontra-se fundamentalmente arraigada na conformação do Estado moderno. Há mais de cinco séculos essa forma de organização política vem pautando as práticas sociais e as relações internacionais entre os povos. Práticas e relações que, todavia, mostram-se hoje relativamente modificadas pelas sucessivas e paulatinas transformações científicas e tecnológicas, passando a exigir da criatividade humana novas formas de organização do poder político. No atual tempo mundial, a soberania clássica se vê, assim, contestada em suas vertentes endógena e exógena. No primeiro caso através de demandas oriundas das unidades infra-estatais, legitimadas pelo apelo democrático que elas encerram; no segundo caso pela necessidade crescente de cooperação entre estados-nações - desembocando mesmo em processos de integração - legitimados pela eficiência econômica que elas asseguram aos seus membros.

Ora, essa necessidade de cooperação remonta à Antigüidade, passa pelo período medieval, para finalmente chegar à Idade Moderna, revelando-se, pois, um fenômeno deveras constante. O que parece ser procurado, desde então, é uma situação de equilíbrio de poder, geradora de harmonia e vetor inibidor de conflitos bélicos, comerciais, culturais ou sociais. Contudo, se a visão teleológica é a mesma, os meios para atingi-la diferem, assumindo por vezes um formato essencialmente estato-cêntrico (realista), por vezes um formato holista com vocação supranacional (transnacionalista).

Em meados do século XVIII, por exemplo, o escocês David Hume, em seu ensaio Of the Balance of Power ${ }^{73}$, apresenta certos elementos nesse sentido. Também o prelado francês Fénelon, bispo de Cambrai, em seu Supplément à l'examen de conscience sur les devoirs de la roy$a^{a} t^{7}{ }^{74}$, reporta-se a noção de equilíbrio de poder sublinhando que um simples ajustamento mecânico das forças presentes não seria uma solução definitiva. Quando o Estados-nações procuram suas seguranças particulares e definem seus interesses comuns, impõe-se o estabelecimento de laços perenes entre eles, ou seja, é mister "fazer uma espécie de sociedade

73 Cf. Hume, David. Essays Moral, Political and Literary. Oxford University Press. 1974.

74 Apud. Truyol y Serra, Antonio. Fénelon, théoricien de l'équilibre européen. in Badie, Bertrand; Pellet, Alain (orgs.). Les relations internationales à l'épreuve de la science politique. Paris, Economica, 1993. 
ou de república geral"75. Ainda, alguns séculos mais tarde, Hans Morgenthau retoma essa problemática em seu Politics among Nations ${ }^{76}$ apontando que "all foreign policies tend to conform to and reflect one of three patterns of activity: maintaining the balance of power, imperialism and what he called the politics of prestige (impressing other states with the extent of one's power)"'77.

Em suma, o que se delineia, grosso modo, é a constituição de dois pólos interpretativos antagônicos - nem sempre bem difinidos - entre os quais se estende uma gama intermediária de compreensões que oscilam, assim, entre postulados realistas e premissas transnacionalistas. É nesse espectro que se situam as diversas modalidades de integração regional e suas respectivas concepções de soberania. Procurando atenuar os efeitos de natureza entrópica que derivam das múltiplas metamorfoses que marcam a história da organização política ocidental, tenta-se repensar a noção de soberania, adaptando-a aos anseios mais prementes de ordem interna e externa.

No que concerne a ordem externa, a secular interpretação tomista volta então à pauta através da idéia de soberania dividida, remetendo o debate a reflexões sobre a pertinência de fórmulas intergovernamentais ou supranacionais. No que toca a ordem interna, as discussões gravitam em torno de temas como autonomia, descentralização ou, ainda, desconcentração. O patamar ocupado pelo Estado-nação encontra-se, dessa maneira, submetido simultaneamente a pressões oriundas das forças subnacionais e supranacionais. A resultante dessa interação sedimenta-se na edificação de um sistema complexo de relações que reflete as novas dimensões de poder de cada instância político-administrativa. Assim, a soberania, ainda que fortemente enraizada no Estado-nação, começa a migrar - através dos diferentes tipos de supranacionalidades - rumo ao aparelho transnacional e, através dele, também em direção da esfera subnacional ${ }^{78}$.

Contudo, observa-se que o advento integracionista - segundo o nível de desenvolvimento de seus componentes e em função da opção feita por eles no que concerne o grau de supranacionalidade a ser implantado -

\footnotetext{
75 Ibid.

76 Cf. Morgenthau, Hans. Politics Among Nations: The Struggle for Power and Peace. New York, Alfred Knopf, 1948.

77 Apud. Griffiths, Martin, op. cit.

78 Em alguns casos, quando seus interesses maiores estejam em jogo, representantes de Länder alemães ou de Comunidades belgas podem ter assento no Conselho de Ministros da União Européia, assumindo assim o poder de decisão.
} 
nem sempre consegue promover um processo igualitário ou pelo, menos, apto a atenuar o caráter marginal de determinados de seus espaços ou segmentos societais. Se, por um lado, a situação econômica é uma variável estrutural que demanda prazo elástico de modificação; por outro lado, a escolha do grau de supranacionalidade a ser adotado reflete deliberadamente uma opção política que, aliás, tem, através de um fenômeno de feedback, incidência considerável sobre a evolução do cenário econômico.

Sem embargo, é a macro-visão que fundamenta a regulação supranacional que facilita a instalação de uma lógica centrífuga e, consequentemente, que aproxima as periferias dos centros. Instaura-se, assim, um processo redistributivo que tenta compensar as disfunções de um sistema ainda em vias de implementação, onde as disputas intestinas, não raro, pecam por falta de racionalidade. Para tal, entretanto, há que se respeitar os preceitos democráticos e, pari passu, acordar a transferência de prerrogativas do Estado-nação para o arcabouço institucional supranacional. Como atesta Amartya Sen, evocando o matemático J. F. Nash, "na presença de vantagens derivadas de uma cooperação, a questão essencial não é de saber se esse ou aquele resultado comum é preferível para todos a uma ausência de cooperação (existe um grande número dessas alternativas), mas se ele engendra uma partilha eqüitativa dos benefícios"79. Tal arranjo é, seguramente, de difícil consecução, e tem sido o alvo da reflexão de estudiosos e tomadores de decisão ao longo dos anos.

Logo, como seus antepassados - e.g. Confederação Beociana, Liga Hanseática ou Confederação Helvética - a União Européia e o Mercado Comum do Sul tentam, cada um à sua maneira, responder às demandas específicas de seus respectivos atores políticos, agentes econômicos e sociedades civis. Contudo, eles não podem deixar de considerar que o interesse comum do processo integracionista é o progresso eqüitativo do conjunto ante uma concorrência internacional implacável, não apenas restrita ao setor econômico, mas estendendo-se igualmente àqueles ligados à cultura ou à religião. Os antecendentes históricos, a realidade econômica, assim como a maturidade política da UE faz com que, não obstante alguns atropelos, sua estrutura institucional tenha tendido, nos últimos anos, em não negligenciar a estratégia supranacional - ancorada, em grande parte, na soberania dividida. O Mercosul, procurando evitar o excesso de formalismo que caracterizou o fracasso de alguns processos de integração na América Latina no passado, refletindo suas assimetrias 
intrínsecas e profundas, e atestando sua condição de processo aglutinador de Estados-nações emergentes opta por um modelo de natureza particularmente intergovernamental. Esse modelo, apesar das rugosidades que tem criado e da penetração que tem alcançado junto à pletora de atores nacionais e subnacionais, sofre da falta de mecanismos supranacionais pelo menos daqueles relacionados à função de proposição e à de controle - para dar coerência e sentido à ação comunitária, assim como para gerar um clima de confiabilidade e criar possibilidades de contestação por parte dos participantes do processo integrador. Claro que, posteriormente, e em função de uma ponderação de votos pertinente, a prática da supranacionalidade de decisão, limitada inicialmente a um setor específico, pode ser inaugurada. Quiçá a introdução desses mecanismos possa facilitar a inserção internacional do Mercosul e estimular o desenvolvimento dos povos que o compõem.

MARCELO DE A. MEDEIROS é professor adjunto de Ciência Política da Universidade Federal de Pernambuco e professor associado de Ciência Política no Institut d'Etudes Politiques d'Aix-en-Provence 


\title{
RESUMOS/ABSTRACTS
}

\section{PRERROGATIVAS ESTATAIS, INTEGRAÇÃO REGIONAL E LÓGICA DISTRIBUTIVA}

\author{
MARCELO de A. MEDEIROS
}

Analisa-se a emergência de um novo paradigma de ordem internacional, baseado em processos de integração regional no lugar do decadente Estado nacional, tendo em vista os limites a ele impostos pela persistência da dinâmica do Estado nacional. Assinala-se a dificuldade para substituir a lógica intergovernamental pela lógica supranacional. A ausência de organizações supranacionais efetivas impõe restrições à distribuição dos ganhos obtidos pela dinâmica integracionista. Examina-se isso com base nos casos do Mercosul e da União Européia.

Palavras-chave: Integração nacional; Mercosul; União Européia; justiça distributiva internacional.

\section{STATE PRERROGATIVES, REGIONAL INTEGRATION, AND DISTRIBUTIVE LOGIC}

The emergency of a new paradigm of international order, based on processes of regional integration instead of the decadent national State is examined in view of the limits imposed on it by the persistence of the dynamics of the national State. The difficulty in substituting a supranational logic for the intergovernmental one is pointed out. The absence of effective supranational organ izations imposes restrictions on the distribution of the gains attained through the integration ist dynamics. This is examined on the basis of the cases of the Mercosul and of the European Un ion.

Keywords: Regional integration; Mercosul; European Un ion; international distributive justice. 